\title{
Urbanization and Economic Development: A Tale of Two Barriers
}

\author{
Eric Bond \\ Raymond Riezman \\ Vanderbilt University \\ University of Iowa, GEP, Ces-ifo \\ Ping Wang \\ Washington University in St. Louis, Federal Reserve Bank of St. Louis, NBER
}

February 2015

\begin{abstract}
In this paper we determine the main driving forces underlying the rapid structural transformation and urbanization process in newly industrialized countries. We use a dynamic, small open economy model with an abundant supply of surplus labor in rural areas, two types of traded goods manufactured in urban areas, and barriers to both trade and migration. The model is supplemented with quantitative analysis using Chinese data. There we focus on determining the role that reductions in trade and migration barriers played in China's growth and urbanization. We find that the primary drivers for real per capita GDP growth are migration cost reduction and skill accumulation. While trade liberalization is important for urbanization during the transition toward China's admission to the WTO (particularly for the employment measure), it does not contribute much to real per capita GDP growth relative to other major changes throughout the development process in China. During this transition process, migration cost reduction and TFP changes are both important, accounting for a significant proportion of increased urbanization.
\end{abstract}

Keywords: Barriers to Migration and Trade, Urbanization and Economic Development, Surplus Labor, Structural Transformation.

JEL Classification Numbers: O41, O11, F16, R23.

Acknowledgment: We are grateful for comments and suggestions by Robert Lucas, Zheng Song, Kei-Mu Yi, Shangjin Wei, Zhihong Yu, and participants at the American Economic Association Meetings. Ting-Wei Lai has provided excellent research assistance.

Correspondence: Raymond Riezman, Department of Economics, University of Iowa, Iowa City, IA 52242; 319-335-1956 (Fax); raymond-riezman@uiowa.edu (E-mail). 


\section{Introduction}

During the post-WWII era, we have witnessed a number of newly industrialized countries with sustained growth, experiencing rapid structural transformation accompanied by greater openness and urbanization. Throughout this development process, there is continual flow of labor relocating from rural agricultural production to urban manufacturing. Rural to urban migration is widely believed as a key component of the development process, but it is sustainable only because of the abundant supplies of "surplus labor" from rural areas. As reported in the table below, even by 2000, rural population in China, India and Thailand still exceeded 60 percent.

\begin{tabular}{c|cccccc}
\hline & China & Egypt & India & Korea & Taiwan & Thailand \\
\hline 1950 & 87 & 68 & 84 & 79 & 76 & 90 \\
2000 & 64 & 55 & 72 & 18 & 21 & 78 \\
\hline
\end{tabular}

Various country studies have found rural surplus labor to account for $13-28$ percent of the total population. ${ }^{1}$ In China for example, rural surplus labor has been estimated in the range of $150-250$ million people. ${ }^{2}$ The large stock of surplus labor has led to very modest growth in the real effective wage rate of unskilled workers in urban areas. ${ }^{3}$

So what are the main driving forces underlying the rapid structural transformation and urbanization process? In the present paper, we address this question in a general dynamic framework with quantitative analysis targeted at the specific experience of China. This is because that not only China had spectacular economic growth over the past three decades, but also facilitated the largest rural-urban migration flows and the sharpest trade liberalization in a short time frame of ten years over the period of 1992-2002. More specifically, we attempt to explore the roles of reductions in trade and migration barriers played in China's growth and urbanization. To do this, we construct a simple, dynamic framework exhibiting the following specific features:

(i) We consider a small open economy with an abundant supply of surplus labor in rural areas at which a nontraded good is produced using unskilled labor with a Ricardian technology.

\footnotetext{
${ }^{1}$ See, for example, Bowlus and Sicular (2003) for the case of China, Hanson (1971) for Egypt, Horowitz (1974) for India, and Bertrand and Squire (1980) for Thailand.

${ }^{2}$ See Laing, Park and Wang (2005).

${ }^{3}$ In China, for example, the growth rate of the real, urban, unskilled (for workers with 9 years of schooling or less) wage has been less than $1 \%$ for the period $1992-2005$.
} 
(ii) There are two types of traded goods manufactured in urban areas: an exportable (processed food, for example) and an import substitutable (laptop computers, for example), where the production of the import-competing goods is more capital and skill intensive.

(iii) Unskilled labor is paid a market wage rate that makes potential migrants from rural areas indifferent between migrating and not migrating.

(iv) There are barriers to both trade and migration - in the case of China, import tariff had been high before its admission to the WTO, and its rigid household registration (hukou, aka hokou in the older literature) system limited rural-urban migration.

With the prevalence of surplus labor, we establish that the migration equilibrium directly pins down the real unskilled wage, which leads to very different comparative-static predictions from the conventional dynamic open-economy models under the Hecksher-Ohlin setting. Under this essentially fixed real unskilled wage, independent of changes in trade or migration barriers, both trade liberalization in forms of tariff reduction and relaxation of migration constraints promote capital accumulation. Moreover, by mitigating trade or migration barriers, such policies encourage allocation of capital and unskilled labor toward the production of the exportables. Furthermore, we establish sufficient conditions under which a reduction in either trade or migration barriers speed up the urbanization process and promotes economic development.

By calibrating the model to fit observations from China over the period of 1980 to 2008, we can conduct counterfactual analysis that determines quantitative significance of the underlying drivers of the process of urbanization and development. We find that the primary drivers for real per capita GDP growth are migration cost reduction and skill accumulation. While trade liberalization is important for urbanization during the transition toward China's admission to the WTO (particularly for the employment measure), it does not contribute much to real per capita GDP growth relative to other major changes throughout the development process in China. During this transition process, migration cost reduction and TFP changes are both important, accounting for a significant proportion of increased urbanization. Overall, a one percent reduction in import tariff generates about one-third percent increase in real GDP per capita and about a quarter percent increase in urbanization.

\section{$\underline{\text { Related Literature }}$}

Our paper is related to three strands of the literature: one on structural transformation, one on surplus labor and the other on migration and growth. 
Since the seminal works by Rostow (1960) and Kuznets (1966), there has been numerous studies on documenting and characterizing structural transformation over the course of economic development. The more recent literature revisits the issues under the dynamic general equilibrium framework. While Laitner (2000) emphasizes the role played by savings in such transformation, Hansen and Prescott (2001) and Ngai and Pissaridis (2007) highlight dominant technology growth of the modern compared to the traditional sector. In Gollin, Parente, and Rogerson (2002), technical progress in the agricultural sector is the main driver to fulfill subsistence, thus enabling reallocation of labor toward modern industries. This type of sectoral transformation is further analyzed by Kongsamut, Rebelo, and Xie (2003) that features a declined share in agriculture, a constant share in manufacturing and a rising share in service, in a non-balanced growth setup with balanced growth in aggregation. While agricultural subsistence is also emphasized in Casselli and Coleman (2001) and Duarte and Restuccia (2010) to study cross-region or cross-country differences in labor productivity, Buera and Koboski (2009) propose an additional key driver - sector-biased technological progress - and Buera and Koboski (2012) highlight the role of scale technologies for mass production in the process of industrialization. For brevity, our review is limited to a small subset of the literature; those interested are referred to a recent survey by Herrendorf, Rogerson, Valentinyi (2013).

There is a large literature on surplus labor economies beginning with important work by development economists such as Lewis (1954), Fei and Ranis (1961, 1964) and Sen (1966) (hereinafter referred to as LFRS). They studied its implication for labor-market performance and economic advancement. Here we extend this tradition to a dynamic, open-economy setting, to examine how the existence of a large supply of rural unskilled labor affects trade, urbanization, capital accumulation, as well as sectoral and aggregate output and social welfare. This is important because international trade is important for many of these surplus labor economies and capital accumulation, of course, is essential in the economic development process. Since the seminal work by LFRS, the implications of rural surplus labor in a dual economy have been widely studies by development economists. The papers by Todaro (1969) and Harris and Todaro (1970, (hereinafter referred to as HT) are perhaps most influential applications of LFRS, where urban unemployment and labor policies are examined under an institutionally fixed minimum wage (above its equilibrium level) in the urban areas.

Among many extensions to HT, we highlight only one strand, which is most relevant to our study, that examines trade and migration. In a seminal paper, Khan (1980) reexamines generalized HT models from the perspective of Heckscher-Ohlin and finds that a uniform subsidy to labor 
with a differential subsidy to capital is optimal (in the sense of second-best). In Batra and Naqvi (1987), gains from trade are evaluated in the presence of urban unemployment and the optimal policy established is a uniform subsidy to labor together with free trade (no tax levied on goods). In Beladi and Marjit (1996), the rural sector employs labor and an intermediate good, while both the intermediate good and the final good sectors in the urban area employ capital and labor. A reduction in tariffs on the urban final good is shown to lower capital rental and to raise urban employment as long as the urban final good sector is capital intensive. Recently, Chang, Kaltanic and Loayza (2009) argue that a reduction in tariff improves production efficiency from the goods market perspective but increases labor market distortions in a simple HT setting.

There is also a closely related literature on surplus labor, migration and growth, initiated by Drazen and Eckstein (1988) and Glomm (1992). Drazen and Eckstein (1988) propose a 2-period overlapping generations framework with land as a specific factor in the rural sector and capital as a specific factor in the urban sector, while Glomm (1992) designs an infinite lifetime model allowing for rural-urban migration where higher urban productivity is a result of lower communication costs associated with higher population density. While the decentralized equilibrium in Drazen and Eckstein is suboptimal, that in Glomm is Pareto optimal. Rural-urban migration has also been used to explain equilibrium low-growth traps under informational asymmetry. For example, Bencivenga and Smith (1997) illustrate such a possibility due to the adverse selection of workers into urban areas, while Banerjee and Newman (1998) achieve a similar goal by considering the modern urban sector to have lower credit availability due to higher agency costs.

The most closely related paper is by Lucas (2004), who addresses the issue of rural/urban migration as a transition from a no-growth agricultural sector using traditional technology to an urban sector where there is persistent growth due to human capital accumulation. Workers in the urban sector must choose their time allocation between human capital accumulation and work. His model explains the existence of a persistent wage differential between the urban and rural sectors as reflecting the return to human capital accumulation that workers must engage in when they migrate to the city. This contrasts with the Harris-Todaro model, where the differential reflects the possibility of spending time in unemployment due to a rigid urban wage.

We next turn to developing our dynamic, open economy model. 


\section{The Model}

We examine a model of a small open economy in which there is a rural sector and an urban sector. In the rural sector, unskilled workers are engaged in subsistence agriculture whose output is consumed only in the rural area. In the urban sector, two tradeable goods are produced using inputs of unskilled labor, skilled labor, and capital. The exportable good, $X$, requires inputs of unskilled labor and is not consumed domestically. The importable good, $Y$, can be either consumed or used for investment purposes, and is produced using inputs of unskilled labor, skilled labor, and capital. The economy's supply of skilled labor and unskilled labor is taken as exogenously given, although the allocation of unskilled labor between the rural and urban sectors is determined by household migration decisions. The supply of capital to the urban sector is assumed to be endogenously determined by the savings decisions of households that own skilled labor. In this section we derive the conditions determining the allocation of unskilled labor between the rural and urban areas, the allocation of income between consumption and investment, and the allocation of capital and unskilled labor between the $X$ and $Y$ sectors in the urban areas.

\subsection{The Rural/Urban Migration Decision}

The exogenously given stock of unskilled labor, denoted $\bar{N}>0$, consists of a group of size $N$ residing in the rural area and a group of size $L$ located in the urban area. By staying in the rural area, an unskilled worker receives a subsistence utility of $\bar{U}$ per period, which represents the payoff received from subsistence farming. By migrating to the city/township area, an unskilled worker earns the unskilled wage $w$ and consumes instead the traded good $Y$. We will choose the world price of good $\mathrm{Y}$ as numeraire, so the domestic price of good $Y$ will be $T_{Y}=(1+\tau)$, where $\tau$ is the ad valorem tariff on imports of $Y$. The consumption of an unskilled worker located in the urban sector at time $t$ will be

$$
c_{Y, t}^{u}=\frac{w_{t}}{T_{Y}}
$$

An unskilled worker receives utility of $\psi U\left(c_{Y, t}^{u}\right)$ from locating in the urban sector, where $\psi \in(0,1]$ and $U$ is strictly increasing and strictly concave, and satisfies the Inada conditions. One may think of $\psi$ as a migration discounting factor, that is, rural workers discount the welfare from earning the urban wage because they are away from home and family. This discount could also reflect training costs are skill accumulation required in order to work in the urban area. In general, this is a wedge that also summarizes the migration barrier. In the quantitative analysis of this paper when we 
calibrate the model to data from China, such barriers capture the migration restrictions as a result of the household registration (hukou) regulations.

Using (1), the migration equilibrium implies:

$$
\psi U\left(\frac{w_{t}}{T_{Y}}\right)=\bar{U}
$$

which pins down the equilibrium real unskilled wage rate, $\frac{w_{t}}{T_{Y}} \cdot{ }^{4}$ This reservation real wage for unskilled labor is driven by $\psi$ which captures the crucial underlying institutional factors regarding rural-urban migration. As long as $\psi<1$, there will be a urban-rural wage gap with the unskilled wage in urban areas exceeding that in rural areas. We will allow for the possibility that $\psi$ can be influenced by government policy, which might influence the amount of rural/urban migration (as in the case of the household registration system in China). When we conduct comparative-static exercises, we will take a constant-elasticity-of-intertemporal-substitution utility form $U=\frac{1}{\nu}\left(c_{Y}\right)^{\frac{1}{\nu}}$, with $\nu>1$ and the elasticity of intertemporal substitution being measured by $\frac{\nu}{\nu-1}$. Under this specification, the migration condition is given by

$$
w=T_{Y}\left(\frac{\bar{U}}{\psi \nu}\right)^{\nu}
$$

The figure below illustrates the determination of the unskilled wage rate in the migration equilibrium.

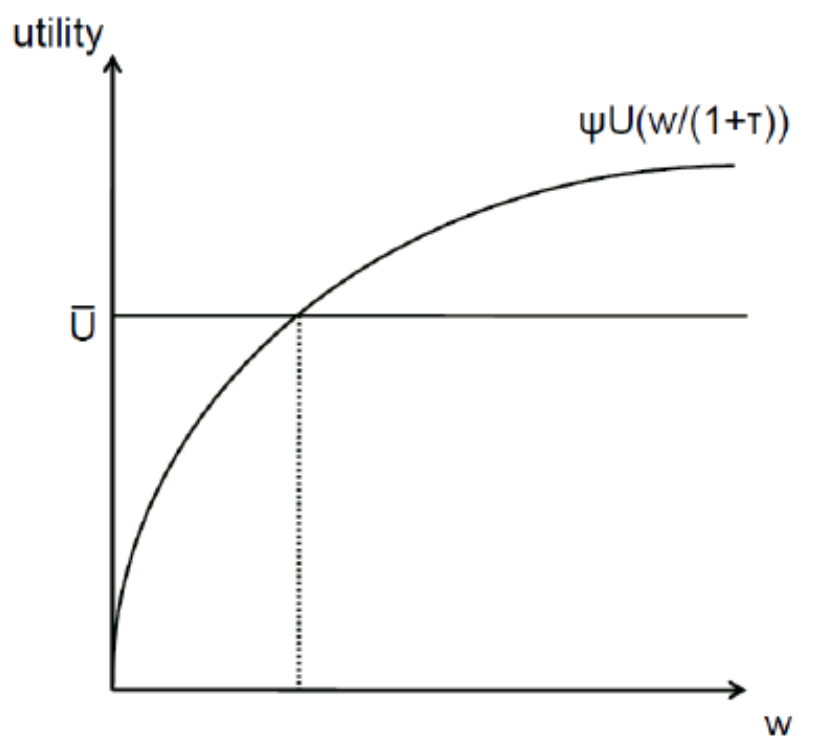

\footnotetext{
${ }^{4}$ Since the unskilled wage will turn out to be constant along the path to the steady state in our formulation, this condition is equivalent to what would be obtained if workers compared the discounted future returns in each location.
} 


\subsection{Capital Accumulation}

It will be assumed that all capital is owned by households that own skilled labor. The stock of skilled labor is assumed to be exogenously given, which we will normalize to unity for simplicity, $\bar{H}=1$. The wage rate earned by skilled workers is denoted $s_{t}$, so the budget constraint at time $t$ for a household owning a unit of skilled labor can be written as

$$
c_{Y, t}^{s}+I_{t}=\frac{s_{t}+r_{t} K_{t}}{T_{Y}}+T_{t}
$$

where $K$ is the stock of capital goods owned by the household, $I$ is investment, $r$ is the return on existing capital, and $T$ is the net transfer from the government in terms of good $Y$. In addition, we assume that capital investment is subject to barriers. Thus, the (beginning-of-period) household capital stock is accumulated according to:

$$
K_{t+1}=(1-\delta) K_{t}+\frac{I_{t}}{\mu\left(I_{t}\right)}
$$

Here $\mu\left(I_{t}\right)>1$ captures the severity of capital investment barriers, with $\epsilon=I \mu^{\prime}(I) / \mu(I) \in(0,1)$ denoting the (constant) elasticity of the capital investment barrier with respect to the level of investment. The marginal cost of investment will be increasing for $\epsilon>0$, and $\epsilon<1$ is required for investment to be productive. ${ }^{5}$ The capital barrier may be viewed as a variant of the conventional investment adjustment cost or the Parente-Prescott (1994) technology adoption barriers. Notably, while the capital barrier is considered to fit the observed high capital rental and high capital output ratio in China, it is not the focus of the present paper.

The saving decision for a skilled worker household can be derived from the Bellman equation:

$$
\begin{aligned}
V\left(K_{t}\right)= & \max _{c_{Y, t}^{s}, I_{t}}\left[U\left(c_{Y, t}^{s}\right)\right]+\frac{1}{1+\rho} V\left(K_{t+1}\right) \\
& \text { s.t. (4) and (5) }
\end{aligned}
$$

where $\rho$ is the rate of time preference. The solution to this optimization problem yields the Euler equation governing intertemporal consumption:

$$
(1+\rho) \frac{U_{c_{Y, t}^{s}}}{U_{c_{Y, t+1}^{s}}}\left(\frac{\mu\left(I_{t}\right)}{\mu\left(I_{t+1}\right)}\right)=\left[1-\delta+\frac{r(1-\epsilon)}{\mu\left(I_{t+1}\right)\left(T_{Y}\right)}\right]
$$

Equation (7) shows that the marginal rate of intertemporal substitution will be equated to the intertemporal relative price on the optimal path. The intertemporal relative price of future consumption is determined by the rental rate on capital, $r$, divided by the marginal cost of a unit of

\footnotetext{
${ }^{5}$ An alternative setup is to assume that capital investment barriers depend on the aggreggate level of investment $\bar{I}$ where $\bar{I}=I$ in equilibrium. Mathematically, this is equivalent to setting the elasticity $\epsilon=0$ in the optimization conditions (MRS) and (MG) below, under which all our main findings remain unchanged.
} 
the investment good, $\mu\left(I_{t+1}\right) T_{Y} /(1-\epsilon)$. Greater investment barriers and larger marginal costs of adjustment will reduce the return to postponing consumption, because they reduce the real return to a unit of capital.

In a steady state, (7) yields the modified Golden Rule:

$$
r=\frac{(\rho+\delta) \mu\left(I_{t}\right) T_{Y}}{1-\epsilon}
$$

Note that the cost of the investment good on the right hand side of (8) is increasing in $I$, because the investment barriers/adjustment costs are increasing $I$. This yields a positive relationship between the steady state return on capital and the steady state investment level, with the elasticity of the steady state investment level with respect to the return on capital given by $1 / \epsilon$.

\subsection{Factor Allocation in the Urban Sector}

We now turn to the determination of factor prices and outputs in the urban sector, which will determine the allocation of factors between the $X$ and $Y$ sectors. Production in each sector is assumed to take place under conditions of constant returns to scale in production and perfect competition.

The exportable is produced using capital and unskilled labor with a Cobb-Douglas technology, $X=B K_{X}^{\theta_{K X}} L_{X}^{\theta_{L X}}$ where $B>0, \theta_{j X}$ is the cost share of factor $j \in\{K, L\}$ in production of good $X$, and $\theta_{K X}+\theta_{L X}=1$. This production technology has the associated unit cost function

$$
C^{X}\left(w, r_{X}\right)=\frac{1}{B}\left(\frac{r_{X}}{\theta_{K X}}\right)^{\theta_{K X}}\left(\frac{w}{\theta_{L X}}\right)^{\theta_{L X}}
$$

where $r_{X}=r$ is the rental on capital paid by firms in the $X$ sector. The producer price of good $X$ is $p T_{X}$, where $p$ is the world price of the exportable, $T_{X} \equiv 1+\eta$, and $\eta$ is the ad valorem export subsidy rate applied to the world price. Assuming that the world price of the exportable and the government policy wedges are constant over time, the zero profit condition for the $Y$ sector at time $t$ will be

$$
C^{X}\left(w_{t}, r_{t}\right)=p T_{X}
$$

This condition must hold with equality if good $X$ is produced at $t$.

The import-competing good is produced with capital, unskilled labor and skilled labor under the following constant-returns technology: $Y=A\left[F\left(K_{Y}, H\right)\right]^{1-\theta_{L Y}} L_{Y}^{\theta_{L Y}}$ where $A>0, \theta_{L Y} \in(0,1)$ is labor's share in unit costs and $F$ is a well-behaved constant-returns-to-scale function satisfying 
$F_{K}>0, F_{H}>0, F_{K K}<0, F_{H H}<0$ and $F_{K H}>0$. The last property ensures capital-skill complementarity in the Pareto sense (i.e., more skilled labor raises the marginal product of capital), which has strong empirical support (e.g., see Griliches 1969 and Krusell et al 2000). Thus, skilled labor is used as a specific factor only in the import-competing sector, which is so assumed for analytical simplicity. ${ }^{6}$ The unit cost function for the $Y$ sector is

$$
C^{Y}\left(w, r_{Y}, s\right)=\frac{1}{A}\left(\frac{G\left(r_{Y}, s\right)}{1-\theta_{L Y}}\right)^{1-\theta_{L Y}}\left(\frac{w}{\theta_{L Y}}\right)^{\theta_{L Y}}
$$

Note that the cost function for the $Y$ sector can be written as $C^{Y}\left(w, r_{Y}, s\right)=\phi\left(w, G\left(r_{Y}, s\right)\right)$, where $G(\cdot)$ is the unit cost function corresponding to the "sub-production function" $F(\cdot)$ and $\phi(\cdot)$ is the unit cost function for the Cobb Douglas function with inputs of unskilled labor and the composite input $F$. The functions $\phi$ and $G$ will be increasing and homogeneous of degree one in their respective input prices, and with negative own and positive cross price effects. By free factor mobility, $r_{Y}=r$. Assuming $Y$ sector tax and tariff policies are constant over time, the zero profit condition will be

$$
C^{Y}\left(w_{t}, r_{t}, s_{t}\right)=T_{Y}
$$

where $T_{Y} \equiv 1+\tau$, and $\tau$ is the import tariff rate. This is to be referred to as the trade barrier, which is the second barrier of our primary interest. The barrier is mitigated under trade liberalization in the forms of tariff reduction.

Equilibrium in the urban factor markets and goods markets will require that firms earn zero profits in each sector, and that the demand for each of the productive factors equal their supply in the urban sector. Using the unit cost functions (9) and (11), the full employment conditions for skilled labor, capital, and unskilled labor can be expressed as:

$$
\begin{aligned}
C_{s}^{Y}\left(w_{t}, r_{t}, s_{t}\right) Y_{t} & =H=1 \\
C_{r}^{X}\left(w_{t}, r_{t}\right) X_{t}+C_{r}^{Y}\left(w_{t}, r_{t}, s_{t}\right) Y_{t} & =K_{t} \\
C_{w}^{X}\left(w_{t}, r_{t}\right) X_{t}+C_{w}^{Y}\left(w_{t}, r_{t}, s_{t}\right) Y & =L=\bar{N}-N_{t}
\end{aligned}
$$

For a given level of factor supplies $\left\{H, K_{t}, \bar{N}\right\}$, the competitive profit conditions $((9)$ and (11)), the migration condition (3), and the full employment conditions ((13)-(15)) will determine the factor prices $\left\{w_{t}, r_{t}, s_{t}\right\}$, output levels, $\{X, Y\}$ and the allocation of unskilled workers to the urban sector, $L$.

\footnotetext{
${ }^{6}$ We could allow skilled labor to be used in the exportable sector as long as it is used less intensively relative to unskilled labor than in the import sector. In this case, the results remain quantitatively unchanged.
} 
We are now able to define real aggregate output, $R$ as

$$
R=\frac{p T_{X}}{T_{Y}} X+Y
$$

\subsection{Budget Balance and Goods Market Equilibrium}

The demand for $Y$ sector output for domestic consumption will be $c_{Y, t}=L_{t} c_{Y, t}^{u}+c_{Y, t}^{s}$. Using the household budget constraints (1) and (4) and letting $M_{t}$ denote the level of imports, we can express the goods market equilibrium condition as

$$
M_{t}=\frac{s_{t}+r_{t} K_{t}}{T_{Y}}+T_{t}+\frac{w_{t} L_{t}}{T_{Y}}-Y_{t}
$$

Given the pair of import tariff and export subsidy $(\tau, \eta)$ and hence $\left(T_{Y}, T_{X}\right)$, the passive government in our model economy simply set transfers $T_{t}$ to balance the budget:

$$
T_{t}=\left(T_{Y}-1\right) M_{t}-\frac{p_{t}\left(T_{X}-1\right)}{T_{Y}} X_{t}
$$

These two equations (17) and (18) can be used to solve for imports $M_{t}$ and government transfers $T_{t}$. Because our focus is on tariff based trade liberalization, in the quantitative analysis we will choose the level of export subsidy such that the government transfer in the steady state is zero. This would eliminate the undesirable artificial redistribution between the skilled and the unskilled.

\section{Equilibrium Characterization}

We now turn to an analysis of the steady state equilibrium for the surplus labor economy. The analysis of the competitive equilibrium is greatly simplified by the fact that the model has a block recursive structure:

(i) the three factor prices can be first solved, independently of the factor supplies or the goods output;

(ii) capital, investment and the outputs of the traded goods are subsequently pinned down;

(iii) the allocation of unskilled labor in the urban sector is then be determined;

(iv) finally, other quantities such as consumption, imports, exports, and government transfers are solved. 
More specifically, the competitive profit conditions, (10) and (12), require that price equal unit cost in a sector at each point in time where it is in operation. Combining these equations with the rural/urban migration condition, (3), yields a recursive system of three equations in the three factor prices $(w, r, s)$. That is, the unskilled wage $w$ is pinned down by the world price of importable and the migration-related institutional factor given in (3). Given the equilibrium value of $w,(10)$ determines the rental $r$ and then (12) determines the skilled wage $s$.

The effect of changes in the two main policy parameters $\left(T_{Y}, \psi\right)$ on factor prices can be determined by total differentiation of the system of equations (10), (12), and (3). It is convenient to express these comparative statics results using the "hat algebra" where $\hat{Z} \equiv \frac{\dot{Z}}{Z}$ :

$$
\begin{aligned}
\hat{w} & =\hat{T}_{Y}-\nu \hat{\psi} \\
\hat{r} & =-\frac{\theta_{L X}}{\theta_{K X}}\left(\hat{T}_{Y}-\nu \hat{\psi}\right) \\
\hat{s} & =\frac{\left(1-\theta_{L Y}\right) \theta_{K X}+\theta_{L X} \theta_{K Y}}{\theta_{K X} \theta_{H Y}} \hat{T}_{Y}-\frac{\theta_{L X} \theta_{K Y}-\theta_{L Y} \theta_{K X}}{\theta_{K X} \theta_{H Y}} \nu \hat{\psi}
\end{aligned}
$$

The existence of surplus labor locks the real wage of unskilled labor into the utility level available in the rural sector, so it will only be affected by policies that affect the cost of migration to the urban areas. With a fixed real wage (in terms of good $Y$ ), the return to capital is increasing in policies that favor the exportable sector and the return to skilled labor is decreasing in policies that favor the exportable sector.

When there are changes (either policy driven or exogenous) in favor of rural-urban migration it mitigates the associated barriers and $\hat{\psi}>0$. It follows then that the unskilled wage is lower and the capital rental higher. Its' effect on the skilled wage is negative if the import-competing sector is more capital intensive in the cost sense relative to the exporting sector (i.e., $\theta_{L X} \theta_{K Y}>\theta_{L Y} \theta_{K X}$ ). Combining (19) and (21), we obtain:

$$
\hat{s}-\hat{w}=\frac{1}{\theta_{K X} \theta_{H Y}}\left[\theta_{K Y} \hat{T}_{Y}-\left(\theta_{K Y}-\theta_{K X}\right) \nu \hat{\psi}\right]
$$

An increase in the relative protection offered to the $Y$ sector relative to the $X$ sector raises the skill premium. Moreover, if the capital cost share in the $Y$ sector exceeds one in the $X$ sector $\left(\theta_{K Y}>\theta_{K X}\right)$, then a change in the institutional factor in favor of rural-urban migration reduces the skill premium. ${ }^{7}$

The following proposition summarizes these results on factor prices:

\footnotetext{
${ }^{7}$ Notice that, even when $Y$ is more capital intensive in the cost sense, the captial cost share in the $Y$ sector need not exceed one in the $X$ sector.
} 
Proposition 1: (Factor Prices) The wage of skilled labor is increasing proportionately with the import tariff with the real unskilled wage being unaffected, whereas the rental on capital is decreasing in the tariff. While a reduction in migration barriers lowers the unskilled wage and raises the capital rate, it suppresses the skilled wage rate if the importable sector is capital intensive in the cost sense.

Due to the abundant availability of surplus labor, the migration equilibrium under our model framework leads to insensitivity of the real unskilled wage in urban areas to trade liberalization in forms of tariff reduction. This may serve to explain, at least partly, why there is little growth in the real effective wage rate of the unskilled workers in urban areas despite the presence of a persistent and significant urban-rural wage gap.

The steady state investment level is positively related to the return to capital from (8), so we can invert that relationship and use the fact that the steady state capital stock will equal $K=I /(\delta \mu(I))$ from (5) to solve for the steady state capital stock,

$$
K=\kappa\left(\frac{r}{T_{Y}}\right)
$$

where $\kappa$ is an increasing function of the real return on capital. Totally differentiating this condition and substituting from (20):

$$
\hat{K}=\gamma\left(-\frac{1}{\theta_{K X}} \hat{T}_{Y}+\frac{\theta_{L X}}{\theta_{K X}} \nu \hat{\psi}\right)
$$

where $\gamma \equiv \frac{1-\epsilon}{\epsilon}>0$. The steady state supply of capital is more elastic the lower is $\epsilon$, where $\epsilon$ is the rate at which the cost of investment increases with the level of investment. From this expression, one can clearly see that the effects of trade-related policies are all magnified when capital supply is more elastic.

Applying the results of Proposition 1 to (23) yields the effects of parameter changes on the steady state capital stock.

Proposition 2: (Capital Accumulation) A reduction in the import tariff or migration barriers raises the steady state capital stock.

That is, both trade liberalization in forms of tariff reduction and relaxation of migration constraints promote capital accumulation.

Given the solution for factor prices, the equilibrium levels of $\left\{X_{t}, Y_{t}, L_{t}\right\}$ can be solved from the full employment conditions for the three urban sector factor markets, (13)-(15). Since skilled labor is used only in the production of good $Y$, the factor prices are determined independently of 
factor supplies, the full employment conditions can be solved recursively for the output levels and the employment of unskilled labor in the urban sector.

With skilled labor being used only in the import-competing sector, the equilibrium output of good $Y$ is determined by (13),

$$
Y=\frac{H}{C_{s}^{Y}(w, r, s)}
$$

With constant factor prices, output of $Y$ will be constant along the path to the steady state. Substituting this solution into (14), we obtain the solution for output $X$ as a function of the stock of capital, $K_{t}$. In the steady state, the capital stock will be given by (22), so that the level of $X$ sector output is given by,

$$
X=\kappa\left(\frac{r}{T_{Y}}\right)-\frac{C_{r}^{Y}(w, r, s) H}{C_{r}^{X}(w, r) C_{s}^{Y}(w, r, s)}
$$

In order to derive the effect of policy changes on the steady state output levels, we will find it useful to derive some preliminary results on the effect of policy changes on the unit factor requirement in each of the traded good sectors. Under the assumption of Cobb-Douglas production function for the $X$ sector, the own price elasticities of the factor demands are given by $r C_{r r}^{X} / C_{r}^{X}=$ $-\theta_{L X}$ and $w C_{w w}^{X} / C_{w}^{X}=-\theta_{K X}$. Utilizing (19) and (20), we have:

$$
\begin{aligned}
& \hat{C}_{w}^{X}=-\hat{T}_{Y}+\nu \hat{\psi} \\
& \hat{C}_{r}^{X}=\frac{\theta_{L X}}{\theta_{K X}}\left(\hat{T}_{Y}-\nu \hat{\psi}\right)
\end{aligned}
$$

A lower relative price of the import-competing good will result in substitution of unskilled labor for capital in the $X$ sector, because the cost of capital is positively related to the relative price of good $X$. Similarly, a reduction in the migration barrier will reduce $w / r$, resulting in substitution of unskilled labor for capital.

The unit cost function for the $Y$ sector takes the form $C^{Y}=\phi(w, G(r, s))$, where $\phi$ is CobbDouglas and $G$ is constant returns to scale. Due to the Cobb Douglas formulation for $\phi$, the unit labor requirement will $C_{w}^{Y}=\theta_{L Y} T_{Y} / w$. Since the real wage is locked in place by the migration condition, (3), the unit labor requirement in $Y$ will respond only to changes in the migration costs, $\psi$. For the input requirements of of capital and skilled labor, we can define the elasticity of demand associated with the sub-production function $F$ as $\eta_{s r} \equiv r G_{s r} / G_{s}>0$ and $\eta_{r s} \equiv s G_{r s} / G_{r}>0$. The constant returns to scale assumption for $G$ then implies $\eta_{s s}=-\eta_{s r}$ and $\eta_{r r}=-\eta_{r s} \cdot{ }^{8}$ Using these

\footnotetext{
${ }^{8}$ If the function $G$ is Cobb-Douglas, $\eta_{s r}=\theta_{K Y} /\left(\theta_{K Y}+\theta_{H Y}\right)=1-\eta_{r s}$.
} 
properties, we further obtain the change in unit labor requirements in the $Y$ sector to be:

$$
\begin{aligned}
\hat{C}_{w}^{Y} & =\nu \hat{\psi} \\
\hat{C}_{r}^{Y} & =\eta_{r s} \frac{\theta_{K Y}+\theta_{H Y}}{\theta_{H Y}}\left(\frac{1}{\theta_{K X}} \hat{T}_{Y}-\frac{1}{\theta_{K X}} \frac{\theta_{L X}-\theta_{L Y}}{\theta_{K Y}+\theta_{H Y}} \nu \hat{\psi}\right) \\
\hat{C}_{s}^{Y} & =\eta_{s r} \frac{\theta_{K Y}+\theta_{H Y}}{\theta_{H Y}}\left(-\frac{1}{\theta_{K X}} \hat{T}_{Y}+\frac{1}{\theta_{K X}} \frac{\theta_{L X}-\theta_{L Y}}{\theta_{K Y}+\theta_{H Y}} \nu \hat{\psi}\right)
\end{aligned}
$$

Comparing (26) and 27), it can be seen that an increase in the relative price of $X$ will result of substitution away from capital in both sectors, and substitution toward the use of skilled (unskilled) labor in the $Y(X)$ sector. A reduction in migration costs will reduce the price of unskilled labor, which increases the demand for skilled labor and reduces the demand for capital in the $X$ sector iff $X$ has a larger unskilled labor cost share than does $Y$.

We are now ready to analyze the effects of the parameters on sectoral outputs and unskilled labor in urban areas. Since $\hat{Y}=\hat{H}-\hat{C}_{s}^{Y}$ from (13), we can totally differentiate (24) and substitute from (27) to obtain:

$$
\hat{Y}=\hat{H}+\eta_{s r}\left(\frac{\theta_{K Y}+\theta_{H Y}}{\theta_{H Y}}\right)\left(\frac{1}{\theta_{K X}} \hat{T}_{Y}-\frac{1}{\theta_{K X}} \frac{\theta_{L X}-\theta_{L Y}}{\theta_{K Y}+\theta_{H Y}} \nu \hat{\psi}\right)
$$

The output in the $Y$ sector is increasing in the import protection, $T_{Y}$. The impact of a reduction in migration costs and capital market subsidies on output of $Y$ reflect the impact of these changes on the demand for skilled labor per unit of output noted above.

Totally differentiating the steady state capital market equilibrium condition (25) and substituting from (26), (27), and (19)-(21) yields,

$$
\hat{X}=-\frac{\Delta+\gamma+\lambda_{K X} \theta_{L X}}{\lambda_{K X} \theta_{K X}} \hat{T}_{Y}+\frac{\left(\frac{\theta_{L X}-\theta_{L Y}}{\theta_{K Y}+\theta_{H Y}}\right) \Delta+\left(\gamma+\lambda_{K X}\right) \theta_{L X}}{\lambda_{K X} \theta_{K X}} \nu \hat{\psi}
$$

where where $\lambda_{K X} \equiv X C_{r}^{X} / K$ denotes the fraction of all capital employed in the $X$ sector and $\Delta \equiv\left(1-\lambda_{K X}\right)\left(\eta_{r s}+\eta_{s r}\right)\left(\frac{\theta_{K Y}+\theta_{H Y}}{\theta_{H Y}}\right)>0$ captures the degree of substitutability between skilled labor and capital in the $Y$ sector. Thus, the output of good $X$ is decreasing in $T_{Y}$. A reduction in migration barriers will increase the output of exportables because it lowers the real cost of unskilled labor. Note also that the short run effects of policy changes (i.e. with a fixed $K_{t}$ ) can be obtained by setting $\gamma=0$. A uniform subsidy to capital in both sectors will have no effect on the output of $X$ in the short run, but will raise output in the long run due to its positive effect on the steady state capital stock.

Results on outputs from (28) and (29) can be summarized as: 
Proposition 3: (Sectoral Outputs) A reduction in the import tariff or the migration barrier raises the output of the exportables but lowers the output of the import-competing good.

The following proposition regarding the effect of the changes in the two barriers on the allocation of factors between sectors follows immediately.

Proposition 4: (Factor Allocations) A reduction in import tariff encourages allocation of capital and unskilled labor toward the production of the exportables and lowers the capital-labor ratios in both sectors. A reduction in migration barriers lowers the exportable sector's capital-labor ratio unambiguously and suppresses the importable sector's capital-labor ratio if the importable sector is capital intensive in the cost sense.

A import tariff reduction lowers the return to producing the importable and hence encourage both factors to be reallocated toward the exportable sector. While the real unskilled wage remains unchanged, the real the real rental rate rises, thus leading to lower capital-labor ratios in both sectors. The intuition underlying the migration barrier reduction follows similarly, only more complication only due to capital intensity considerations.

We are now prepared to examine the extent of rural-urban migration governed by the mass of unskilled workers in the urban area $L$. This can be done by totally differentiate the unskilled labor market clearing condition (15) and apply (26) and (27):

$$
\begin{aligned}
\hat{L} & =\lambda_{L X}\left(\hat{X}+\hat{C}_{w}^{X}\right)+\left(1-\lambda_{L X}\right)\left(\hat{Y}+\hat{C}_{w}^{Y}\right) \\
& \left.=-\frac{\Gamma+\lambda_{L X}\left(\gamma+\lambda_{K X}\right)}{\lambda_{K X} \theta_{K X}} \hat{T}_{Y}+\frac{\left(1-\lambda_{K X}\right)\left(\theta_{L X}-\theta_{L Y}\right)\left(\frac{\Gamma}{\theta_{K Y}+\theta_{H Y}}+\frac{\lambda_{L X} \lambda_{K X} \eta_{r s}}{\theta_{H Y}}\right)+\lambda_{L X}\left(\gamma \theta_{L X}+\lambda_{K X}\right)}{\lambda_{K X} \theta_{K X}}(\hat{30})\right)
\end{aligned}
$$

where $\lambda_{L X}=X C_{w}^{X} / L$ is the share of urban unskilled labor employed in the $X$ sector and $\Gamma \equiv$ $\left[\left(\lambda_{L X}-\lambda_{K X}\right) \eta_{s r}+\lambda_{L X}\left(1-\lambda_{K X}\right) \eta_{r s}\right]\left(\frac{\theta_{K Y}+\theta_{H Y}}{\theta_{H Y}}\right)$. To see the effect via $\Gamma$, we note that if the $X$ sector is unskilled labor intensive relative to $Y$ in the quantity sense (i.e., $\lambda_{L X}>\lambda_{K X}$ ), then one obtains $\Gamma>0$. From (30), this factor intensity condition is also sufficient for a reduction in import tariff to raise urban employment of the unskilled. However, $\Gamma>0$ is not necessary for this result because tariff reduction also has a positive impact on the steady state capital (as long as $\gamma>0$ ), and a higher steady state capital stock will raise the demand for unskilled labor by increasing its marginal product. Moreover, should the import-competing sector be capital intensive in the quantity sense but sufficiently labor intensive in the cost sense such that $\theta_{L X}<\theta_{L Y}$, then the factor intensity condition $\lambda_{L X}>\lambda_{K X}$ is also sufficient for a reduction in rural-urban migration barriers to induce urban employment of unskilled workers. Thus, these conditions on factor intensity rankings 
ensure "mobility normality" in the sense that a lower barrier encourages migration. Summarizing these results, we have:

Proposition 5: (Urbanization) When the import-competing sector more capital intensive in the quantity sense, a reduction in the import tariff speeds up the urbanization process. When the import-competing sector is more capital intensive in both quantity and cost sense, a reduction in the migration barrier promotes urbanization.

We conclude our equilibrium characterization by examining the effect of changes in the two barriers on the steady-state aggregate manufacturing output (in units of the import-competing goods). Defining the output share of the $X$ sector as $\chi$ (and hence that of the $Y$ sector as $1-\chi$ ), we can totally differentiate (16) to yield,

$$
\begin{aligned}
\widehat{R} & =\chi\left(\hat{X}-\hat{T}_{Y}\right)+(1-\chi) \hat{Y} \\
& =-\frac{1}{\theta_{K X}}\left[\Upsilon+\chi\left(1+\frac{\gamma}{\lambda_{K X}}\right)\right] \hat{T}_{Y}+\left[\frac{\left(\theta_{L X}-\theta_{L Y}\right) \Upsilon}{\theta_{K X}\left(\theta_{K Y}+\theta_{H Y}\right)}+\chi\left(1+\frac{\gamma}{\lambda_{K X}}\right) \frac{\theta_{L X}}{\theta_{K X}}\right] \nu \hat{\psi}
\end{aligned}
$$

where $\Upsilon \equiv \chi \frac{\Delta}{\lambda_{K X}}+(1-\chi) \eta_{s r} \frac{\theta_{K Y}+\theta_{H Y}}{\theta_{H Y}}>0$ if the import-competing sector is capital intensive in the quantity sense to which we restrict our attention. Then, a reduced trade protection offered to the $Y$ sector leads to greater aggregate manufacturing output because the benefit from import competing outweighs the loss from export expansion. Moreover, the long-run effect of mitigating migration barriers raises aggregate manufacturing output if the import-competing sector is also capital intensive in the cost sense, which together with the intensity assumption in the quantity sense assures mobility normality. Summarizing the above findings yields:

Proposition 6: (Aggregate Manufacturing Output) When skilled workers receive zero net real transfer from the government, when the import-competing sector more capital intensive in the quantity sense, a reduction in the import tariff raises aggregate manufacturing output. When the importcompeting sector is more capital intensive in both quantity and cost sense, a reduction in migration barriers also raises aggregate manufacturing output.

Whether these factor intensity conditions hold true and how large the urbanization and output effects of a reduction in trade and migration barriers would be are both quantitative issues, to which we now turn. 


\section{Quantitative Analysis}

To investigate how reduction in trade and migration barriers speeds up the urbanization process and promotes economic development quantitatively, we calibrate the model to fit observations from China over the period of 1980 to 2008 . China is selected not only because it had large trade and migration barriers, but also because it experienced one of the most prominent reductions in each barrier over the past decade or two. Both economic institutional reforms are related to the Southern Trip of Deng Xiao-Ping in 1992 when market orientation and international openness announcement. Two key open policies were permission to foreign direct investments and application to joining the WTO. Concerning the latter - an important reduction in the trade barrier, China's average effective import tariff rate was about 33.5\% prior to 1995; from 1995 to 2001 in transition to being a member of the WTO, the figure became about $14.8 \%$; this figure was further reduced to $5.84 \%$ since the inception into the WTO in 2002. Also in conjunction with the market and trade reforms, the hukou system was relaxed in 1995 to enable more rural-urban migration so as to accommodate the expected needs for a much larger labor force in the urban areas. Based on survey data from several provinces, Liao, Wang, Wang and Yip (2014) estimate such a migration cost reduction to be $15 \%$ approximately. These trade and migration barriers as well as their reductions will be the key elements in the quantitative exercises.

To incorporate the aforementioned drastic changes in trade and migration barriers, we will divide the entire sample period into three regimes:

(i) Regime 1 (1980-1994): this subperiod featured high import tariff and restricted migration regulation by Hukou;

(ii) Regime 2 (1995-2001): this subperiod experienced transitional reduction in tariff and much relaxed migration regulations;

(iii) Regime 3 (2002-2008): this subperiod had low import tariff obeying the WTO guides and continued the adoption of relaxed migration regulations.

In each regime, we will also adjust a few major changes to better fit the data. For example, since 1999, there was a drastic expansion of college admissions with the students enrolled under the new regime graduating and joining the labor force in summer 2002. This is translated into an increase in the supply of the skilled labor in our model. Moreover, for the sake of simplicity, we have not modeled the urban service sector, but its expansion is even faster than the manufacturing sector 
during the post-1992 period. In our calibration analysis, we extend the model by allowing for an urban service sector to grow proportionately to the urban manufacturing sector (the aggregate of exportable and import-competing sectors) and to have the same skill proportion as in the manufacturing sector. Both the service employment share and the skill proportion are allowed to vary across the three regimes. Furthermore, the total labor force population is adjusted by data in each regime and the relative productivity between the two urban manufacturing sectors is calibrated to fit some key moments in the calibration. We will summarize all such cross-regime differences at the end of the next subsection.

\subsection{Calibration}

In the calibration analysis, the utility function is assumed to be $\log \operatorname{linear}, \ln (c)$, the production function of the importable to be Cobb-Douglas, and the capital barrier function $\mu(I)$ to take an iso-elastic form, $\mu(I)=\mu_{0} I^{\epsilon}$.

Following the standard in the dynamic macro and growth theory literature, we choose the subjective time discount rate as $\rho=0.03$ and the capital depreciation rate as $\delta=0.05$. We normalize the average skilled labor in the urban manufacturing sector over the entire period to be $H=1$ and the reservation value to be $\bar{U}=1$. The urban-rural unskilled wage ratio is set at $\varpi=2$, as documented in the rural-urban migration literature (cf. see the papers cited in Liao, Wang, Wang and Yip 2014).

We begin by matching the average moments over the entire sample period of 1980-2008. When we are constrained by data availability, a short period of 1992-2008 is used. Based on the average effective tariff rate over 1992-2008, we have $\tau=15.0 \%$. A major task of the calibration exercise is to construct an exportable sector and an import-competing sector. Using 2 digit sectoral data covering 29 manufacturing industries over 1992-2008 (a later starting year due to data limitation), we apply each sector's export and import content and output to compute the aggregate outputs of exportables and importables ( $X$ and $Y$, respectively). For brevity, we relegate the details to the Appendix. Once such a categorization is done, we then use sectoral employment data, capital data

and skilled proportion data to back out sectoral allocation of unskilled labor and capital under the assumption that all skilled workers are in the import-competing sector. Based on sectoral wages and skilled proportions, we can also compute the average skilled and unskilled wage rates. By further assuming capital rental at $20 \%$ that is consistent with the existing literature on China, the above information enables us to compute the following ratios: (i) capital income share in 
the exporting sector $=\beta=0.528$; (ii) capital income share in the import-competing sector $=$ $\alpha_{K}=0.600$; (iii) skilled wage income share in the import-competing sector $=\alpha_{H}=0.072$; (iv) skill premium $=s / w=1.55 ;(\mathrm{v})$ the unskilled labor share and the capital share in the exporting sector are $\frac{L_{X}}{L}=57.8 \%$ and $\frac{K_{X}}{K}=45.6 \%$, respectively; and, (vi) sectoral productivity growth rates measured by the rates of change of Solow residuals rates $g_{A}=1.14 \%$ and $g_{B}=2.56 \%$, respectively (indicating, not surprisingly, faster productivity growth of the exportable sector compared to the import-competing sector). Under these technology parameters, it is easily verified that the importcompeting sector is capital intensive in both quantity and cost sense.

We then calibrated the remaining parameters as well as unobserved variables based on the model. To fit the unskilled labor and capital shares in the exporting sector with a $10 \%$ capital barrier, we obtain: $\mu_{0}=0.1761$ and $\epsilon=0.4940$, which imply $I=40.809$ and $\mu=1.1$ (noting that $\mu=1$ implies no capital barrier). Using $\bar{U}=1$, the observed skill premium and the migration equilibrium condition, we can solve the unskilled and the skilled wage $w=6.2520$ and $s=9.6907$, as well as the migration discounting factor $\psi=0.5906$. Further applying the two competitive profit conditions and the trade balance condition and setting the net transfer to be zero, we can calibrate $A=1.6835, B=1.7470, p=0.9866$ and $\eta=0.1765$, so the sectoral TFP ratio is $A / B=0.96364$. Finally, under the normalization of $H=1$ and given the observed service sector employment share in the urban area $\zeta=22.9 \%$, we can compute the employment of the unskilled in urban manufacturing $L=16.732$ and back out the employment in the urban service sector $N_{S}=5.2668$. Thus, the urbanization rate (measured by employment) is given by:

$$
v=\frac{L+H+N_{S}}{\bar{N}+H+N_{S}}
$$

By matching the average urbanization rate of $v=29.4 \%$ over the period of 1980-2008, we can then compute the total unskilled population as $\bar{N}=71.962$ and the total working population as $P O P=\bar{N}+H+N_{S}=78.229$. With identical skilled proportion in urban manufacturing and service sectors, the skilled proportion is given by, $\sigma=\frac{H}{H+L}=5.64 \%$. We can then compute the population of the unskilled and the skilled in the urban areas, denoted $\bar{L}$ and $\bar{H}$ respectively, as:

$$
\begin{aligned}
\bar{L} & =\frac{(1-\zeta \sigma) L+\zeta(1-\sigma) H}{1-\zeta}=21.702 \\
\bar{H} & =\frac{\zeta \sigma L+[1-\zeta(1-\sigma)] H}{1-\zeta}=1.2970
\end{aligned}
$$

That is, about $5.6 \%$ of urban workers are skilled and about $28.1 \%$ of the unskilled (and, by construction, $100 \%$ of the skilled) are working in urban areas. 
Moreover, to evaluation the performance of the macroeconomy, we need to compute real GDP per capita. To do so, we first construct a price index: ${ }^{9}$

$$
P=\left(p T_{X}\right)^{\xi}\left(T_{Y}\right)^{1-\xi}
$$

where $\xi$ is the weight of the exportable sector. In our calibrated steady-state equilibrium, the manufacturing output share of the exportable sector is $\frac{X}{R}=48.3 \%$. It is thus reasonable to set $\xi=0.5$ over time (which would be kept constant throughout all counterfactual exercises). Now, real manufacturing output using this price index is given by.

$$
\frac{p T_{X} X+T_{Y} Y}{P}=\left(\frac{p T_{X}}{T_{Y}}\right)^{1-\xi} X+\left(\frac{p T_{X}}{T_{Y}}\right)^{-\xi} Y
$$

By including the service sector, real urban output becomes:

$$
\frac{1}{1-\zeta}\left[\left(\frac{p T_{X}}{T_{Y}}\right)^{1-\xi} X+\left(\frac{p T_{X}}{T_{Y}}\right)^{-\xi} Y\right]
$$

To calculate real GDP, we need to incorporate rural output,

$$
\left(\frac{p T_{X}}{T_{Y}}\right)^{1-\xi} \frac{w}{\varpi} N
$$

where $\frac{w}{w}$ is the rural wage. This can be added to real urban output to yield real GDP:

$$
R G D P=\frac{1}{1-\zeta}\left[\left(\frac{p T_{X}}{T_{Y}}\right)^{1-\xi} X+\left(\frac{p T_{X}}{T_{Y}}\right)^{-\xi} Y\right]+\left(\frac{p T_{X}}{T_{Y}}\right)^{1-\xi} \frac{w}{\varpi} N
$$

In the benchmark economy, real GDP per capita (more precisely, per worker) is: $\frac{R G D P}{P O P}=5.7065 .{ }^{10}$ We can then compute the urban output share as:

$$
\varphi=\frac{\frac{1}{1-\zeta}\left[\left(\frac{p T_{X}}{T_{Y}}\right)^{1-\xi} X+\left(\frac{p T_{X}}{T_{Y}}\right)^{-\xi} Y\right]}{R G D P}=66.4 \%
$$

Finally, it is noted that about $48.8 \%$ of import-competing goods are imported and the trade dependence ratio measured by total imports and exports as a ratio of GDP is about $49.9 \%$. These untargeted moments are overall in line with the data - the respective figures are $41.9 \%$ and $45.6 \%$.

With the above benchmark economy calibrated, we now turn to the 3 regimes, where, in each regimes, the total working population $P O P$, skill proportions $\sigma$, and service employment shares $\zeta$ are recalculated based on average data whereas sectoral TFP ratios $A / B$ are recalibrated.

\footnotetext{
${ }^{9}$ While the steady-state measure of $R$ in units of the importables is valid, prices are changing over time and hence we must construct a price index to recompute real output without using numeraire.

${ }^{10}$ Notice that this real GDP per capita figure is computed with the average skill labor in the urban manufacturing sector normalized to one and the price index of 1980 set to 100.
} 
(i) Regime 1 (1980-1994): high tariff $\tau=\tau^{H}=0.335$, restricted migration regulation by Hukou with $\psi=\psi^{L}=0.546427$, low college admission with $H=H^{L}=0.463378$, low working population $P O P=P O P^{L}=71.34489$, low service employment share $\zeta=\zeta^{L}=0.178$, and high sectoral TFP ratio $A / B=A^{H} / B^{H}=1.06854$;

(ii) Regime 2 (1995-2001): intermediate tariff $\tau=\tau^{M}=0.148$, relaxed migration regulation by Hukou with $\psi=\psi^{H}=0.640823$, low college admission with $H=H^{L}=0.463378$, intermediate working population $P O P=P O P^{M}=83.705079$, intermediate service employment share $\zeta=\zeta^{M}=0.270$, and intermediate sectoral TFP ratio $A / B=A^{M} / B^{M}=0.920668 ;$

(iii) Regime 3 (2002-2008): low tariff $\tau=\tau^{L}=0.0584$, relaxed migration regulation by Hukou with $\psi=\psi^{H}=0.640823$, high college admission with $H=H^{H}=3.285563$, high working population $P O P=P O P^{H}=89.181112$, high service employment share $\zeta=\zeta^{M}=0.310$, and low sectoral TFP ratio $A / B=A^{L} / B^{L}=0.840637$.

Notably, the migration wedge $\psi$ is computed based on consumption-equivalent measure for the relaxed regimes (Regimes 2 and 3) to feature a 15\% lower migration cost compared to the restricted regime (Regime 1). Also, other things being equal, the reduction in the sectoral TFP ratios over time (to match the observed sectoral TFP growth rates) would slow down the urbanization and development process. In reality, this potential detrimental effect is outweighed by reductions in trade and migration barriers as well as increases in skill and the service proportions.

\subsection{Basic Results}

The benchmark values of key variables including most importantly the urban output share and the urbanization rate (measured by employment) are reported in first row of the Table below. In rows 2 to 4 , we report the comparable figures under the 3 regimes.

\begin{tabular}{l|ccc|c|cc}
\hline & \multicolumn{3}{|c|}{ Sectoral Shares } & \multirow{2}{*}{ Real GDP } & \multicolumn{2}{c}{ Urban Share } \\
\cline { 2 - 3 } & labor & capital & output & per capita & output & employment \\
\cline { 2 - 3 } & $\frac{L_{X}}{L}$ & $\frac{K_{X}}{K}$ & $\frac{X}{R}$ & $\frac{R G D P}{P O P}$ & $\varphi$ & $v$ \\
\hline Benchmark 1980-2008 & $57.8 \%$ & $45.6 \%$ & $48.3 \%$ & 5.706 & $66.4 \%$ & $29.4 \%$ \\
\hline Regime 1: 1980-1994 & $60.6 \%$ & $47.9 \%$ & $44.8 \%$ & 4.048 & $60.2 \%$ & $26.0 \%$ \\
\hline Regime 2: 1995-2001 & $58.2 \%$ & $46.0 \%$ & $55.5 \%$ & 5.975 & $68.9 \%$ & $30.3 \%$ \\
\hline Regime 3: 2002-2008 & $56.4 \%$ & $44.2 \%$ & $54.2 \%$ & 9.634 & $75.4 \%$ & $36.2 \%$ \\
\hline
\end{tabular}


The results deliver three main messages. First, most noticeably, both the urban output share and the urbanization rate rose sharply over time. Second, real GDP per capita also increased sharply, particularly in the later period when China grew as the World Factory since its inception into the WTO. Third, and somewhat unexpectedly, the sectoral shifts are different than a simple HecksherOhlin would have predicted. Following a trade liberalization in forms of import tariff reduction, one would expect a reallocation from import-competing to exportable sectors. It is not the case here with the prevalence of surplus labor. What we see here is modest allocation of unskilled labor and physical capital toward the import-competing sector. We will explore in the counterfactual analysis below why this occurred.

\subsection{Counterfactual Analysis}

In this section, we will conduct counterfactual analysis by individually setting important parameters, one at a time, in Regime 2 (Regime 3) to their values in Regime 1 (Regime 2). We can then conduct decomposition analysis to examine the contribution of each parameter to real GDP growth and urbanization.

\begin{tabular}{l|ccc|c|cc}
\hline & \multicolumn{2}{|c|}{ Sectoral Shares (\%) } & \multirow{2}{*}{ Real GDP } & \multicolumn{2}{c}{ Urban Share (\%) } \\
\cline { 2 - 3 } & labor & capital & output & \multirow{2}{*}{ per capita } & output & employment \\
\cline { 2 - 3 } & $\frac{L_{X}}{L}$ & $\frac{K_{X}}{K}$ & $\frac{X}{R}$ & $\frac{R G D P}{P O P}$ & $\varphi$ & $v$ \\
\hline Regime 1: 1980-1994 & 60.6 & 47.9 & 44.8 & 4.048 & 60.2 & 26.0 \\
\hline Regime 2: $1995-2001$ & 58.2 & 46.0 & 55.5 & 5.975 & 68.9 & 30.3 \\
\hline Regime 3: 2002-2008 & 56.4 & 44.2 & 54.2 & 9.634 & 75.4 & 36.2 \\
\hline
\end{tabular}

Case 1: Counterfactual for Regime 2 (changing parameter value as it were in Regime 1)

\begin{tabular}{l|lll|l|ll}
\hline a. when $\tau^{M}$ is raised to $\tau^{H}$ & 46.4 & 34.6 & 42.7 & 5.820 & 67.2 & 28.3 \\
\hline b. when $\psi^{H}$ is lowered to $\psi^{L}$ & 44.2 & 32.6 & 38.0 & 4.774 & 63.9 & 28.7 \\
\hline c. when $A^{M} / B^{M}$ becomes $A^{H} / B^{H}$ & 82.2 & 73.8 & 68.9 & 5.409 & 65.0 & 28.9 \\
\hline
\end{tabular}

Case 2: Counterfactual for Regime 3 (changing parameter value as it were in Regime 2)

\begin{tabular}{l|lll|l|ll}
\hline a. when $\tau^{L}$ is raised to $\tau^{M}$ & 46.6 & 34.8 & 43.5 & 9.406 & 74.0 & 34.2 \\
\hline b. when $H^{H}$ is lowered to $H^{L}$ & 65.3 & 53.5 & 71.0 & 7.155 & 72.6 & 34.0 \\
\hline c. when $A^{L} / B^{L}$ becomes $A^{M} / B^{M}$ & 67.7 & 56.1 & 59.9 & 8.790 & 72.0 & 33.8 \\
\hline
\end{tabular}

To begin, referring to sectoral shares, we can see that if there were no reduction in the trade barrier in forms of import tariff (Case 1a and Case 2a), sectoral reallocation works in the same 
way as Hecksher-Ohlin theory, namely, protection leads to resources allocated toward the protected sector. Similarly, because the import-competing sector uses unskilled labor less intensively, higher migration cost (i.e., a lower migration wedge $\psi$ ) would have encouraged resource reallocated toward the import-competing sector. On the contrary, the import-competing sector uses skilled labor more intensively, less availability of skilled labor would have led to less resource for the import-competing sector.

Next, we shift our focus to the more interesting indicators concerning urbanization and economic development, measured by urban output/employment shares and real GDP per capita, respectively. It is informative to decompose the changes in urbanization and economic development into the respective factors: (i) tariff and migration cost reduction and TFP changes in Case 1 and (ii) tariff reduction, skill expansion and TFP changes in Case 2. The decomposition results are reported in the table below.

\begin{tabular}{l|c|cc}
\hline & Real GDP & \multicolumn{2}{|c}{ Urban Share } \\
\cline { 3 - 4 } Decomposition Analysis (all in \%) & per capita & output employment \\
\cline { 2 - 4 } & $\frac{R G D P}{P O P}$ & $\varphi$ & $v$ \\
\hline
\end{tabular}

Case 1: Counterfactual for Regime 2

\begin{tabular}{l|r|rr}
\hline a. contribution of tariff reduction & 8.0 & 19.5 & 46.5 \\
\hline b. contribution of migration cost reduction & 62.3 & 57.5 & 37.2 \\
\hline c. contribution of TFP ratio change & 29.4 & 44.8 & 32.6 \\
\hline d. contribution of population change and service expansion & 0.3 & -21.8 & -16.3 \\
\hline
\end{tabular}

Case 2: Counterfactual for Regime 3

\begin{tabular}{l|r|rr}
\hline a. contribution of tariff reduction & 2.4 & 1.9 & 5.5 \\
\hline b. contribution of skill expansion & 25.7 & 3.7 & 6.1 \\
\hline c. contribution of TFP ratio change & 8.8 & 4.5 & 6.6 \\
\hline d. contribution of population change and service expansion & 63.1 & 89.9 & 81.8 \\
\hline
\end{tabular}

Looking at what explains real per capita GDP growth the primary drivers are migration cost reduction, skill accumulation, population growth slowdown, and service expansion. It is striking that tariffs explain less than $10 \%$ of real per capita GDP growth in both counterfactuals. Considering urban output and employment shares, tariffs are important for the transition from Regime 1 to 2, especially for employment. In this transition, migration cost reduction and TFP changes are also important, accounting for more than $30 \%$ of increased urbanization. It is somewhat surprising 
that TFP contributes more to urbanization than to real per capita GDP growth. In the transition from Regime 2 to 3 after China was admitted to the WTO, the main contribution to urbanization is due to population growth slowdown and service expansion.

\subsection{Further Discussion}

Upon digesting the counterfactual results, one may inquire whether trade liberalization in forms of import tariff reductions has sizable impacts on sectoral allocations, urbanization and economic developments when migration costs, skill accumulation, working population and service proportions all remain unchanged. This is worth further examination because the low relative contribution of tariff reduction in both regime changes might be due to even larger scales of changes in other underlying drivers. To suit the purpose here, we thus restrict our attention to elasticity measures, which are unit free, independent of the sizes of the changes. To be brief, we only report results based on the entire sample period over 1980-2008.

\begin{tabular}{l|ccc|c|cc}
\hline \multirow{2}{*}{ Elasticities w.r.t. 1\% Tariff Reduction } & \multicolumn{3}{|c|}{ Sectoral Shares } & \multirow{2}{*}{ Real GDP } & \multicolumn{2}{c}{ Urban Share } \\
\cline { 2 - 4 } & labor & capital & output & per capita & output & employment \\
\cline { 2 - 7 } & $\frac{L_{X}}{L}$ & $\frac{K_{X}}{K}$ & $\frac{X}{R}$ & $\frac{R G D P}{P O P}$ & $\varphi$ & $v$ \\
\hline Benchmark Case $(\psi=0.5906$ and $\mu=1.1)$ & $1.40 \%$ & $1.41 \%$ & $1.35 \%$ & $0.33 \%$ & $0.23 \%$ & $0.25 \%$ \\
\hline Alternative Scenarios with different migration & barriers and capital barriers & & \\
\hline higher migration barrier $\left(\psi=\psi^{L}=0.546427\right)$ & $2.45 \%$ & $1.98 \%$ & $2.04 \%$ & $0.30 \%$ & $0.26 \%$ & $0.22 \%$ \\
\hline lower migration barrier $\left(\psi=\psi^{H}=0.640823\right)$ & $0.86 \%$ & $1.01 \%$ & $0.90 \%$ & $0.36 \%$ & $0.20 \%$ & $0.30 \%$ \\
\hline higher capital barrier $(\epsilon \downarrow$ with $\mu=1.2)$ & $0.96 \%$ & $1.10 \%$ & $0.99 \%$ & $0.41 \%$ & $0.22 \%$ & $0.37 \%$ \\
\hline lower capital barrier $(\epsilon \uparrow$ with $\mu=1.0001)$ & $2.48 \%$ & $1.97 \%$ & $2.05 \%$ & $0.27 \%$ & $0.24 \%$ & $0.20 \%$ \\
\hline
\end{tabular}

The results suggest that tariff reductions have large - mostly more-than-proportional - effects on sectoral allocations. Such reallocation effects are larger when migration barriers are high or capital barriers are low. While the trade liberalization effects on real GDP per capita and urbanization rates are not as large due to the opposing forces discussed above, they are by no means negligible. For instance, in the benchmark case, a one percent reduction in import tariff generates about onethird percent increase in real GDP per capita and about a quarter percent increase in urbanization rates (by output or employment measures). While the effects on real GDP per capita and urban 
employment agglomeration become larger when migration barriers are low or capital barriers are high, the effects on urban production increase when the opposite is true.

\section{Concluding Remarks}

We have developed a model that we have used to examine the main driving forces for developing countries with surplus labor that have experienced rapid growth and urbanization. We use a dynamic, open economy framework with surplus labor. Given the surplus labor, we find very different comparative-static predictions from the conventional dynamic open-economy models under the Hecksher-Ohlin setting. Both trade liberalization, in the form of tariff reduction and relaxation of migration constraints promote capital accumulation. Moreover, mitigating trade or migration barriers, leads to the allocation of capital and unskilled labor toward the production of exportables. We also establish sufficient conditions under which a reduction in either trade or migration barriers speeds up the urbanization process and promotes economic development.

We have also calibrated the model to fit observations from China over the period of 1980 to 2008. We find that the primary drivers for real per capita GDP growth are migration cost reduction and skill accumulation. While trade liberalization is important for urbanization during the transition toward China's admission to the WTO (particularly for the employment measure), it does not contribute much to real per capita GDP growth relative to other major changes throughout the development process in China. During this transition process, migration cost reduction and TFP changes are also important, accounting for a significant proportion of increased urbanization. Overall, a one percent reduction in import tariff generates about one-third percent increase in real GDP per capita and about a quarter percent increase in urbanization rates by both output and employment measures. 


\section{References}

[1] Banerjee, A. V. and A. F. Newman (1998), "Information, the Dual Economy, and Development," Review of Economic Studies, 65, 631-653.

[2] Batra, R. N. and N. Naqvi (1987), "Urban Unemployment and the Gains from Trade," Economica, 54, 381-395.

[3] Beladi, H. and S. Marjit (1996), "An Analysis of Rural-Urban Migration and Protection," Canadian Journal of Economics, 29, 930-940.

[4] Bencivenga, V. R. and B. D. Smith (1997), "Unemployment, Migration, and Growth," Journal of Political Economy, 105, 582-608.

[5] Bertrand, T. and L. Squire (1980), "The Relevance of the Dual Economy Model: A Case Study of Thailand," Oxford Economic Papers, 32, 480-511.

[6] Bowlus, A. J. and T. Sicular (2003), "Moving Toward Markets? Labor Allocation in Rural China," Journal of Development Economics, 71, 561-583.L. Brandt, C. Hsieh, and X. Zhu, "Chinas structural transformation," Mimeo, University of California, Berkeley, 2005.

[7] Buera, F. and J. Kaboski (2009), "Can traditional theories of structural change fit the data?," Journal of the European Economic Association, 7, 469-477.

[8] Calvo, G. A. (1978). "Urban Unemployment and Wage Determination in LDC's: Trade Unions in the Harris-Todaro Model," International Economic Review, 19, 65-81.F.

[9] Caselli, F. and W. Coleman II (2001), "The U.S. structural transformation and regional convergence: A reinterpretation," Journal of Political Economy, 109, 584-616.

[10] Chang, R., L. Kaltanic and N. V. Loayza (2009), "Openness can Be Good for Growth: The Role of Policy Complementarities," Journal of Development Economics, 90, 33-49.

[11] Drazen, A. and Z. Eckstein (1988), "On the Organization of Rural Markets and the Process of Economic Development," American Economic Review, 78, 431-443.

[12] Duarte, M. and D. Restuccia (1970), "The role of the structural transformation in aggregate productivity," The Quarterly Journal of Economics, 125, 129-173, 2010.mployment and development: A two-sector analysis," American Economic Review, 60, 126-142.

[13] Fei, J. C. H. and G. Ranis (1964), Development of the Labor Surplus Economy: Theory and Policy, Homewood, Illinois: Richard D. Irwin for the Economic Growth Center, Yale University.

[14] Glomm, G. (1992), "A Model of Growth and Migration," Canadian Journal of Economics, 25, 901-922 
[15] Griliches, Z. (1969), "Capital-Skill Complementarity," Review of Economics and Statistics, 51, 465-468.

[16] Harris, J. R. and M. P. Todaro (1970), "Migration, Unemployment and Development: A Two-Sector Analysis," American Economic Review, 60, 126-142.

[17] Hanson, J. A. (1971), "Employment and Rural Wages in Egypt: A Reinterpretation," American Economic Review, 61, 492-499.

[18] Herrendorf, B., R. Rogerson, and A. Valentinyi, "Two perspectives on preferences and structural transformation," National Bureau of Economic Research, 2009.

[19] Jones, R. W. (1971), "A Three Factor Model in Theory, Trade and History," in J. Bhagwati, R. Jones, R. Mundell and J. Vanek (eds.), Trade, Balance of Payments and Growth, Amsterdam: North-Holland.

[20] Khan, M. A. (1980), "The Harris-Todaro Hypothesis and the Heckscher-Ohlin-Samuelson Trade Model : A Synthesis," Journal of International Economics, 10, 527-547.

[21] Krusell, P., L. E. Ohanian, J.-V. Rios-Rull and G. L. Violante (2000), "Capital-Skill Complementarity and Inequality: A Macroeconomic Analysis," Econometrica, 68, 1029-1053.

[22] S. Kuznets (1963), "Quantitative aspects of the economic growth of nations: Distribution of income by size," Economic Development and Cultural Change, 11, 1-80.

[23] Kuznets, S. (1966), Modern Economic Growth: Rate, Structure, and Spread, New Haven: Yale University Press.

[24] Laing, D., C. Park, and P. Wang (2005), "A Modified Harris-Todaro Model of Rural-Urban Migration for China," in F. Kwan and E. Yu (eds.), Critical Issues in China's Growth and Development, Farnham: Ashgate Publishing Limited, 245-264.

[25] Laitner, J. (2000), "Structural change and economic growth," Review of Economic Studies, $67,545-561$.

[26] Lewis, W. A. (1954), "Economic Development with Unlimited Supplies of Labor," Manchester School, 22, 139-191.

[27] Lucas, R. E. Jr. (2004), "Life Earnings and Rural-Urban Migration," Journal of Political Economy, 112, S29-S59.

[28] Ngai, L. and C. Pissarides (2007), "Structural change in a multi-sector model of growth," American Economic Review, 97, 429-443.

[29] Parente, S. and E. Prescott (1994), "Barriers to Technology Adoption and Development," Journal of Political Economy, 103, 298-321. 
[30] Ranis, G. and J. C. H. Fei (1961), "A Theory of Economic Development," American Economic Review, 51, 533-565.

[31] Rostow, W. W. (1960), The Stages of Economic Growth: A Non-Communist Manifesto, Cambridge: Cambridge University Press.

[32] Sen, A. K. (1966), "Peasants and Dualism with or without Surplus Labor," Journal of Political Economy, 74, 425-450.

[33] Song, M. Z., K. Storesletten, and F. Zilibotti (2011), "Growing like China," American Economy Review, 101, 202-241.

[34] Todaro, M. P. (1969), "A Model of Labor Migration and Urban Unemployment in Less Developed Countries," American Economic Review, 39, 138-148. 


\section{Appendix}

A major task in our calibration analysis is to construct the exportable and the import-competing sectors based on employment, capital, output, and trade (imports and exports) data from twodigit industries, labelled by $i$. First, we compute the following employment and output shares by exports/imports in each year:

$$
\begin{aligned}
\sum_{i}\left(\frac{L_{i t}}{L_{t}}\right) E X_{i t} & =E \hat{X}_{t}^{L} ; \sum_{i}\left(\frac{Y_{i t}}{Y_{t}}\right) E X_{i t}=E \hat{X}_{t}^{Y} \\
\sum_{i}\left(\frac{L_{i t}}{L_{t}}\right) I M_{i t} & =I \hat{M}_{t}^{L} ; \sum_{i}\left(\frac{Y_{i t}}{Y_{t}}\right) I M_{i t}=I \hat{M}_{t}^{Y}
\end{aligned}
$$

from which we can obtain their average (mean) values: $\mu\left(E \hat{X}_{t}^{L}\right), \mu\left(E \hat{X}_{t}^{Y}\right) \mu\left(I \hat{M}_{t}^{L}\right) \mu\left(I \hat{M}_{t}^{Y}\right)$. By definition,

$$
E X_{t}=\sum_{i} E X_{i t} ; I M_{t}=\sum_{i} I M_{i t}
$$

Straightforward aggregation implies:

$$
\sum \frac{E X_{i t}}{E X_{t}} N_{i t}=\hat{N}_{t}^{x} ; \sum \frac{E X_{i t}}{E X_{t}} Y_{i t}=\hat{Y}_{t}^{x} ; \hat{N}_{t}^{x}+\hat{N}_{t}^{M}=\hat{N}_{t} ; \hat{Y}_{t}^{x}+\hat{Y}_{t}^{M}=\hat{Y}_{t}
$$

By population identity, we have:

$$
N_{t} \begin{cases}H_{t} & \left\{\begin{array}{l}
\hat{H}_{t}^{x} \\
\hat{H}_{t}^{M}
\end{array}\right. \\
L_{t} & \left\{\begin{array}{l}
\hat{L}_{t}^{x} \\
\hat{L}_{t}^{M}
\end{array}\right.\end{cases}
$$

which implies:

$$
\hat{L_{t}^{x}}=N_{t}^{x} ; \hat{L}_{t}^{M}=(1-\bar{\theta}) N_{t}^{M} ;{\hat{L_{t}}}^{X}=\hat{N}_{t}-{\hat{L_{t}}}^{M}-\hat{H}_{t}{ }^{H}
$$

To compute all components of employment, we assume:

$$
\hat{H}_{t}^{M}=\bar{\theta} N_{t}^{M}
$$

Using limited sectoral skilled labor data $H_{i \hat{t}}(\hat{t}=1995,2004,2008)$, we have:

$$
\sum_{i}\left(\frac{I M_{i \hat{t}}}{I M_{\hat{t}}}\right) H_{i \hat{t}}=\hat{H}_{\hat{t}}^{M}
$$

We then use $\theta_{t} \equiv \frac{\hat{H}_{t}^{M}}{\hat{N}_{\hat{t}}^{M}}$ to obtain $\bar{\theta} \equiv \mu\left(\theta_{t}\right)$, which can be subsequently substituted into the above population identities to compute all components of employment. 